\title{
SEVERE ULCERATION AND LUPOID REACTION OF THE SKIN FOLLOWING B.C.G. VACCINATION
}

\author{
MARY H. BUNNEY, M.B., B.S., M.R.C.S., L.R.C.P. \\ Dermatologist to Headquarters, Scotland *
}

SUMMARY: Two cases of prolonged ulceration following B.C.G. vaccination are reported, The importance of the site of vaccination is stressed, not only on account of lymphatic drainage but in consideration of vulnerability to constant trauma and sources of infection. The presence of secondary infection should be suspected in all cases of excessive or prolonged ulceration. The possibility of lupus vulgaris as a long term sequela of severe B.C.G. vaccination reaction is discussed.

\section{Introduction}

Detailed instructions for the correct procedure in B.C.G. vaccination are clearly set out in "Memorandum on Immunological Procedures" (1968) available to all medical officers. Attention is drawn to the importance of the site of vaccination with regard to lymphatic drainage, and to the necessity for skilled intradermal injection to avoid the ulceration which can occur if the vaccine is injected subcutaneously; an indication of the nature and treatment of severe reactions is also given.

The following case reports may help to underline the importance of adhering to these instructions for a different but equally important reason.

\section{Case reports}

In July 1968 Heaf tests were carried out on 400 soldiers at their depot by the unit medical officer. Twenty soldiers gave a negative reaction and were subsequently vaccinated with standard B.C.G. vaccine (Glaxo) in August 1968. The site of vaccination in each case was the front of the left forearm about 2 inches below the antecubital fossa. Five of these twenty men developed ulcers on the site of vaccination. Two of these healed spontaneously, one healed quickly with simple local treatment, but the remaining two developed large indolent ulcers which were still unhealed in February 1969 (twentysix weeks after vaccination), when they were referred for dematological opinion.

Case 1. Lance Corporal M. Aged 24 years, infantryman.

B.C.G. Vaccination was performed as described above in August 1968. Swelling and redness at the site of the injection occurred within one to two days and increased until by November 1968 ulceration had occurred. Paraffin gauze dressings were applied but the ulcer failed to heal. He had had a previous B.C.G. vaccination in 1962 with no untoward reaction.

Examination in February 1969 revealed a large granulating ulcer approximately $2.5 \mathrm{~cm}$ in diameter, surrounded by an area of bluish-red induration on the left forearm (Fig. 1). No adenitis was present. Marks of a positive Heaf test performed four weeks previously were still clearly visible on the right forearm. Large numbers of coagulase-

* Captain, Royal Army Medical Corps, 1943-1944. 
positive Staphylococcus aureus (penicillin-resistant) were cultured from a swab taken from the surface of the ulcer. No tubercle bacilli were detected by examination or culture. Treatment with Soframycin ointment and Sofratulle was instituted. Four weeks later, the ulcer had healed completely but with severe scarring. The surrounding area of skin retained a brownish discolouration (Fig. 2).

The patient was instructed to protect the area with a dry dressing for a further period.

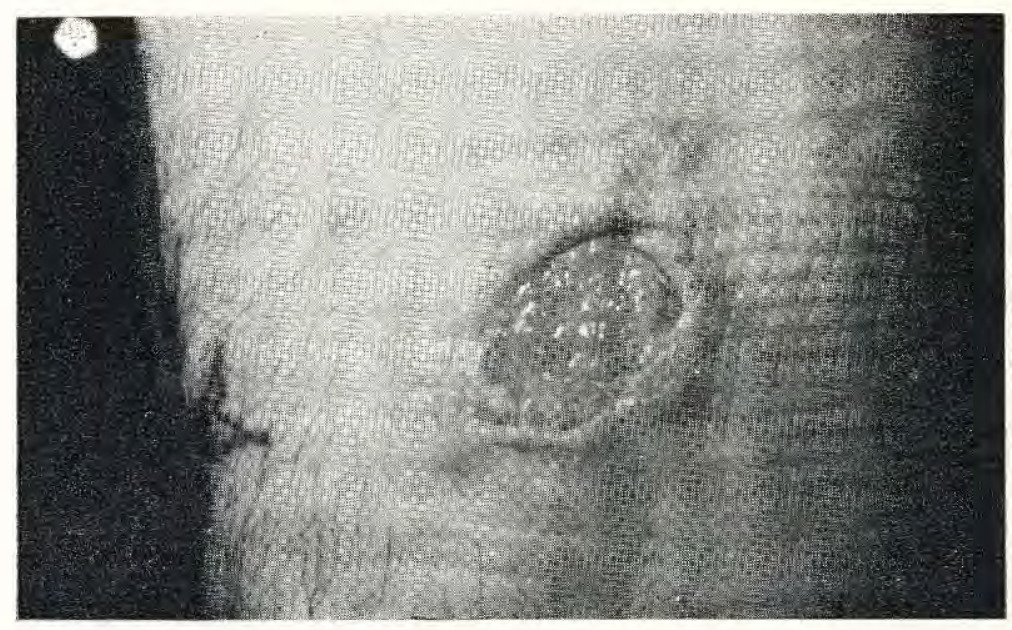

Fig, 1. Case 1 on 12 December 1969. Showing ulcer on left forearm with surrounding lapoid-like granulomatous area.

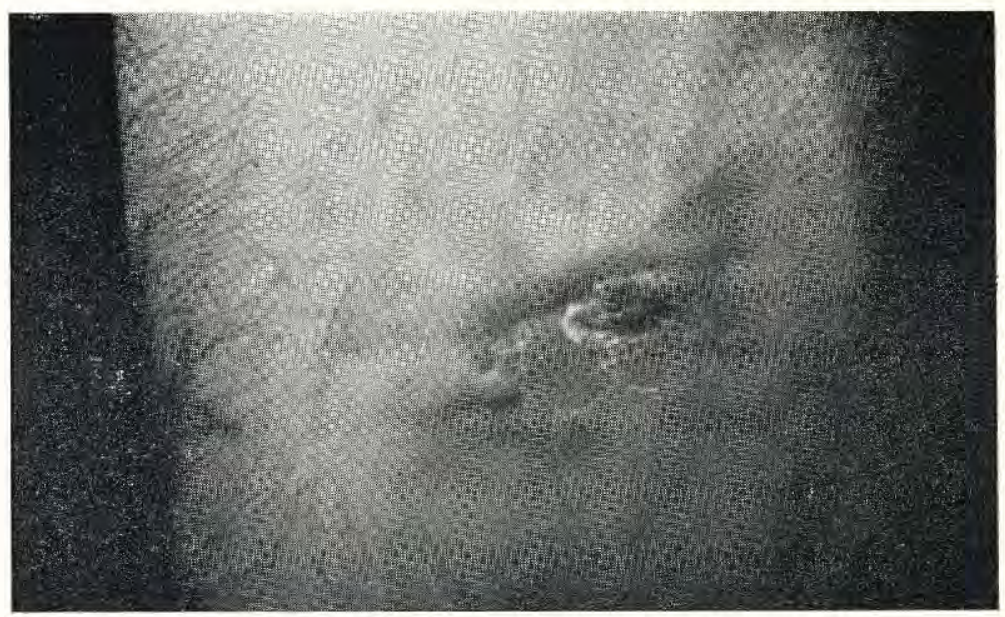

Fig. 2. Case 1 on 13 March 1969. Ulcer is now healed. Scar tissue and surrounding discoloured indurated area remain. 
Case 2. Private W. Aged 24 years, infantryman.

B.C.G. vaccination was performed on the same occasion and in the same manner as in Case 1. No abnormal reaction was noticed for several weeks, after which a reddishblue swelling appeared at the site of injection, reaching the size of a golf ball by December 1968, when a small deep ulcer appeared at the centre. The soldier does not appear to have reported sick but kept the ulcer covered as best as he could with a first aid dressing. There had been no previous B.C.G. vaccination or history of contact with tuberculosis.

When he was referred for dermatological opinion in February 1969, a reddishblue indurated swelling about $2.5 \mathrm{~cm}$ in diameter with a deep, oozing and punched-out ulcer $(10 \times 18 \mathrm{~mm})$ at the centre, was present on the left forearm (Fig. 3) and marks of the Heaf test were clearly seen on the right forearm.

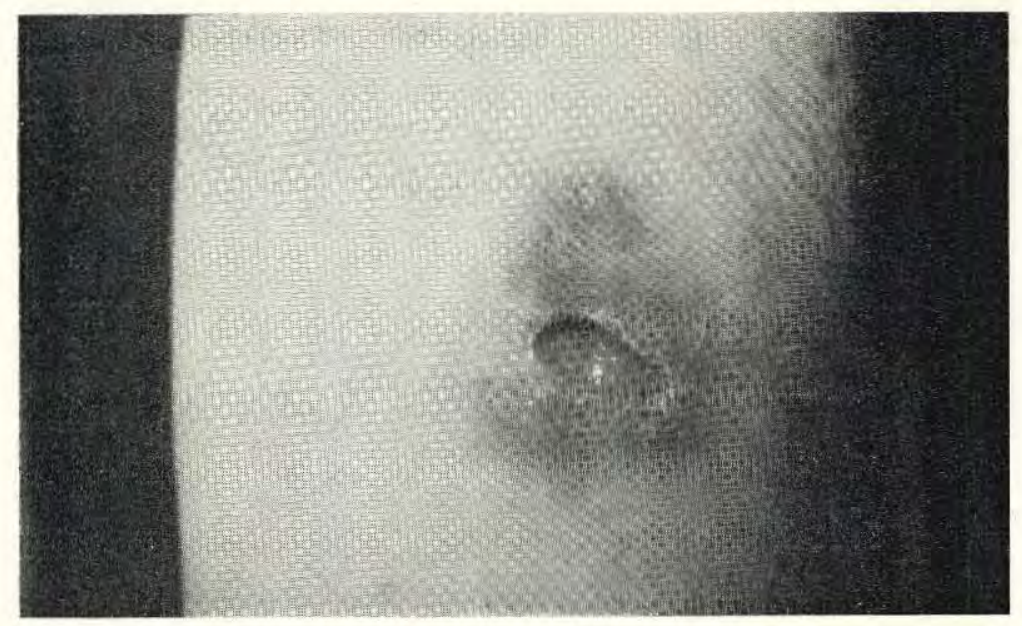

Fig. 3. Case 2 on 12 February 1969. Showing indurated bluish-red granulomatous area with central punched out ulcer.

A fully sensitive coagulase-positive Staphylococcus aureus was cultured from a swab taken from the ulcer, again no tubercle bacilli were seen or cultured. Treatment with Soframycin ointment and Sofratulle effected healing of the ulcer, with scarring, in eight weeks. The surrounding skin, however, remained indurated and retained the bluish-red discolouration (Fig. 4). The patient was instructed about protection of the area.

In June 1969 he developed a new ulcer, $5 \mathrm{~mm}$ in diameter above the site of the previous one but within the area of induration (Fig 5). This occurred a few days after the institution of "shirt sleeve order". As he had thought the area to be soundly healed, he had stopped wearing a protective dressing. Staphylococcus aureus was again cultured from the lesion and healing obtained by the application of Soframycin dressings.

In view of this second episode of ulceration it was felt that a biopsy was justified. This was taken from a non-ulcerated but granulomatous area. Half of the specimen so obtained was examined histologically and reported as follows: 


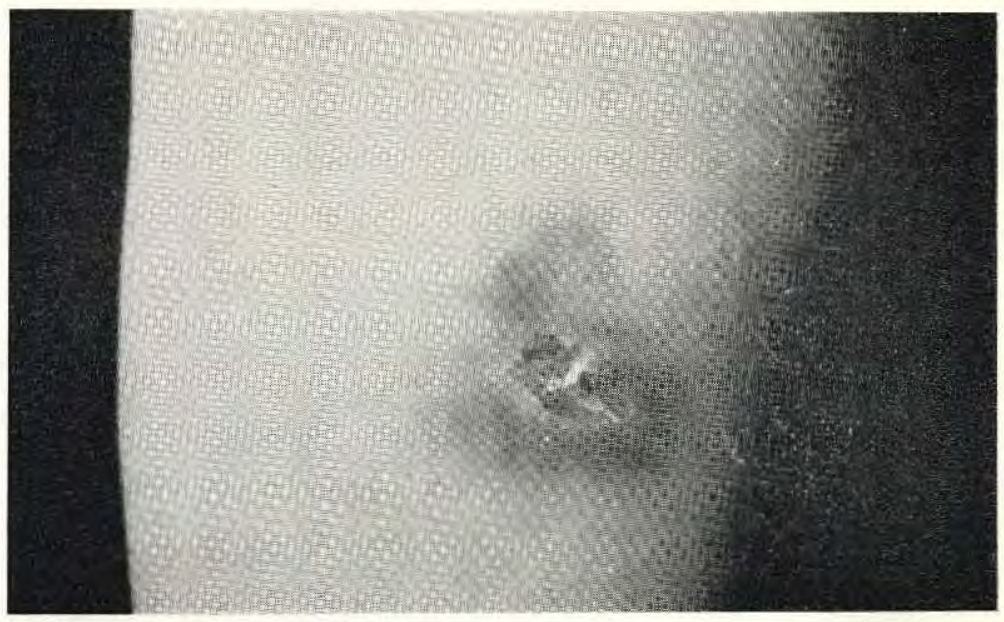

Fig. 4. Case 2 on April 1969. Showing ulcer healed with scarring and residual area of discolouration and induration.

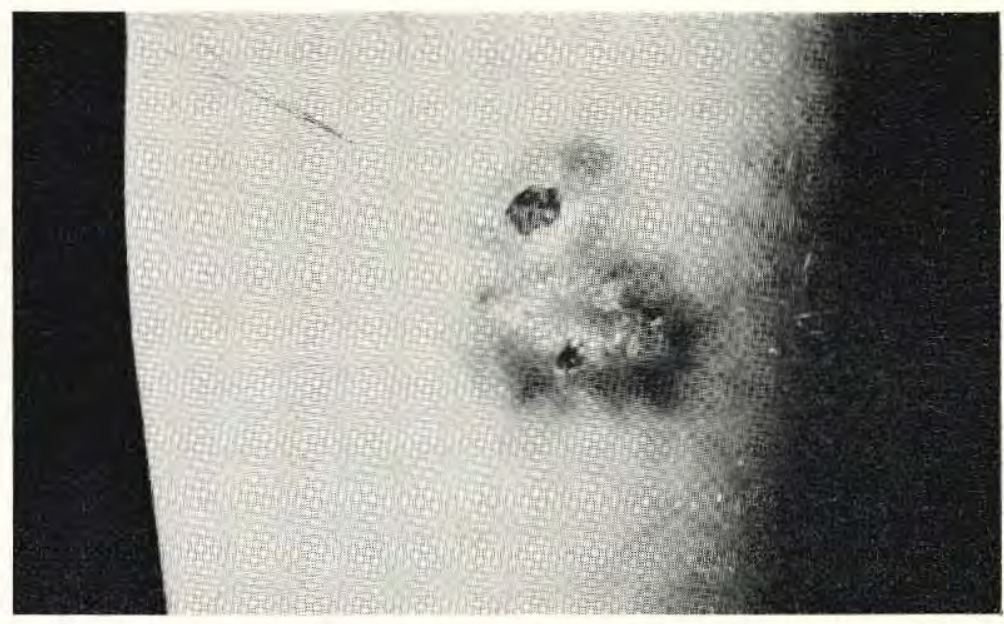

Fig. 5. Case 2 on 3 July 1959. Showing new ulcer.

" The epidermis is acanthotic particularly towards one end of the section where the granular and keratin layers are increased. In the upper dermis there are dilated thin walled blood vessels surrounded by a moderate number of lymphocytes and histiocytes. Here there are also numerous coarse brown granules, doubtless haemosiderin, mostly lying free. In the deep dermis there is a chronic granuloma composed largely of histiocytes and lymphocytes with, in places, necrobiotic foci of connective tissue containing epitheloid cells and giant cells of Langhans type. Some fine granules are present, some within histiocytes. No significant birefringent particles are visible and no acid-fast bacilli were detected.

Chronic granuloma consistent with B.C.G. lupoid reaction." 


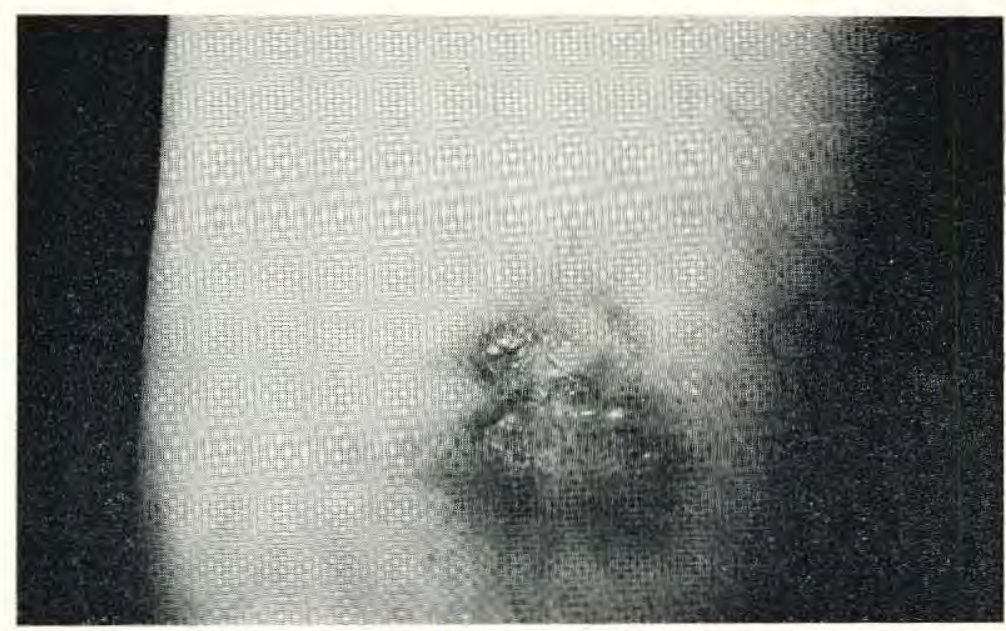

Fig. 6. Case 2 on 26 September 1969. Residual scarring and small area of induration.

The second half of the specimen was inoculated on to four slopes each of LowensteinJensen medium, and pyruvate medium as devised by Stonebrick (1957) especially for the cultivation of Mycobacterium bovis, which does not grow well on the LowensteinJensen medium. No growth had occurred on any of the slopes after twelve weeks incubation, nor were acid-fast bacilli found in smears from the surface of the slopes.

The biopsy incision healed by first intention, but there was subsequent relapse of uiceration following inadequate protection of the area.

When inspected in September 1969 (thirteen months after the vaccination) the areas appeared firmly healed. The surrounding skin showed a brownish pigmentation but only a very small area at the periphery was indurated (Fig. 6). The importance of protecting the area was once more stressed to the patient. He remains under review.

\section{Discussion}

Frew, Davidson and Reid (1955) in their comparison of local reactions from B.C.G. and Vole vaccination report a high incidence of ulceration following the use of both vaccines in children. The ulcers varied from $4-8 \mathrm{~mm}$ in diameter and healed completely in nine to twenty-six weeks. The late cosmetic results in all cases were good.

Wylie, Bennett and Swithinbank (1954) stress the importance of secondary infection and repeated trauma in the formation of severe ulcers and lupoid reactions, although they referred to Vole vaccination. They considered that the high incidence of these reactions in mentally subnormal children was largely due to these factors; the only case observed in a mentally normal adult was in a patient where the site of vaccination had been subjected to persistent intermittent trauma. Crofton (1968) also is of the opinion that trauma and secondary infection are as much responsible for indolent ulceration as subcutaneous injection of the vaccine. These conclusions are well illustrated by the cases under review, in particular by Case 2 . The forearm is a site subjected to constant trauma and exposure to sources of infection. In the light of the experience 
gained from these cases; and their rapid response to topical antibiotic treatment, it is suggested that all ulcers of more than $8 \mathrm{~mm}$ diameter, in which healing is delayed, should be examined for secondary bacterial infection. The forearm should never be used as a site for B.C.G. vaccination.

Marcussen (1954) reports on three cases of lupus vulgaris following B.C.G. vaccination seen at the Finsen Institute and mentions three others previously reported. He comments on the factors predisposing, and the slow development of this condition. In his opinion a severe B.C.G. reaction provides just such a climate and such cases should be kept under review for at least five years.

In Case 2, where a histologically proven lupoid reaction had been provoked, the question of anti-tubercular therapy was considered and rejected in view of the negative cultures and the clinical progress of the condition. In view, however, of Marcussen's findings it will be of interest to keep this case under long term review.

\section{Acknowledgements}

I should like to express my thanks to the unit medical officer concerned for his consent to the publication of these cases, to Professor P. J. Hare for the histological report and Doctor A. T. Wallace for carrying out mycobacteriological investigations.

\section{REFERENCES}

Crofton, J. W. (1968). Personal communication.

Frew, W. H. O., DAvidson, J. R. and ReId, J. T. W. (1955). Brit. med. J. i, 133.

MARCUSSEN, P. V. (1964). Brit. J. Derm. 66, 121.

Stonebrick, B. (1957). Proc. Tuberc. Res. Coun. 44, 67.

Wylie, J. A. R., BennetT, D. H. and Swithinbank, J. (1954). Thorax 9, 190.

The Guthrie Memorial Medal

Professor (Brigadier) Sir John Bruce, Kt., C.B.E., T.D., M.D., F.R.C.S. (Ed.), has been awarded The Guthrie Memorial Medal for 1970. It is awarded to Honorary Consultants for outstanding services to the Army.

Sir John Bruce is Honorary Consultant in Surgery to the Army in Scotland, and a member of the Army Medical Advisory Board. 